\title{
Temperature Effects of GaN HEMTs on the Design of Power Converters
}

\author{
Al Mehdi Bouchour ${ }^{1,2}$, Pascal Dherbécourt ${ }^{1}$, Olivier Latry ${ }^{1}$, Ahmed El Oualkadi $^{2}$ \\ \{al-mehdi.bouchour@univ-rouen.fr, pascal.dherbecourt@univ-rouen.fr, OLivier.latry@univ-rouen.fr\} \\ ${ }^{1}$ GPM UMR CNRS 6634 Normandie Univ, INSA Rouen, CNRS, Rouen, France \\ ${ }^{2}$ Laboratory of Information and Communication Technologies, National School of Applied Sciences of \\ Tangier, Abdelmalek Essaadi University, Tanger, Morocco
}

\begin{abstract}
This paper proposes an experimental study of temperature effects on Gallium Nitride (GaN) High Electron Mobility Transistors (HEMTs). The output and transfer characteristics are monitored at temperatures ranging from $5^{\circ} \mathrm{C}$ to $105^{\circ} \mathrm{C}$. The temperature dependency on static parameters of GaN HEMT is examined, such as: drain current (IDs), on-state resistance $\left(\mathrm{RDS}_{\mathrm{ONN})}\right)$, transconductance $\left(\mathrm{g}_{\mathrm{m}}\right)$, threshold voltage $\left(\mathrm{V}_{\mathrm{TH}}\right)$ and the gate leakage current (IGSs). The decreases of IDs and $g_{m}$ accompanied with the increase of $\mathrm{R}_{\mathrm{DS}(\mathrm{ON})}$ and $\mathrm{I}_{\mathrm{GSS}}$ when increasing temperature have been observed. Moreover, the decrease in electron mobility with increasing temperatures is considered to be one of the causes of the reduction in the drain current and transconductance. In order to study the impact of temperature on power converters with GaN HEMTs by simulation approach, the thermal characteristics of a $650 \mathrm{~V}, 30 \mathrm{~A}$ GaN HEMT have been modelled. The used model is a nonsegmented Electro-thermal SPICE model of Motorola. The model parameters are extracted using Levenberg-Marquardt Algorithm.
\end{abstract}

Keywords: characterization; modeling; temperature; GaN; HEMT; LevenbergMarquardt.

\section{Introduction}

The global renewable energy consumption is estimated to increase by $78 \%$ within 2040 [1].

The use of Gallium Nitride $(\mathrm{GaN})$ power transistors in the renewable energy industry, enable $20 \%$ power density increase, $50 \%$ power loss reduction, $10 \%$ lower system cost, and more efficient energy storage systems, along with bi-directional power flow architectures that are not achievable with silicon (Si) [2].

Furthermore, GaN HEMTs power transistors can operate at higher power levels, frequencies and temperatures, and with an improved energy efficiency with respect to that guaranteed by $\mathrm{Si}$ devices [3]. These excellent features are due to the excellent physical properties of $\mathrm{GaN}$ semiconductor [4]. In fact, they can allow a reduction of the on-state resistance and parasitic capacitances with respect to Si devices, with an overall reduction of the power losses [5]. The above advantages of the $\mathrm{GaN}$ semiconductor make $\mathrm{GaN}$ power transistors attractive for renewable energy domain in particular for use in photovoltaic and wind energy systems [6].

In this context, DC-DC power converters are the most inevitable electronic units in power electronic systems, by providing the control and management of the electric power [7]. The investigation of the temperature dependency of GaN HEMT power transistors is vital to the use 
of the GaN HEMTs in power converter applications. Such an investigation is important particularly to understand the cause of deterioration of their electrical performance at elevated temperatures.

In the literature, several studies on the temperature dependency of GaN HEMTs were performed. References [8] and [9] indicate the evolution of GaN HEMTs electrical parameters during thermal stresses depending on the different temperature ranges.

In this paper, current-voltage characteristics of a GaN HEMT power transistor at operating temperatures are studied experimentally. Moreover, the physics underlying various hightemperature operations of current-voltage characteristics is discussed. Finally, the effect of temperature on power converters with GaN HEMT is verified by a simulation approach.

\section{Static characterization}

The tested device is a GS66508P from GaN Systems [10]. It is a p-type gate normally-off $\mathrm{AlGaN} / \mathrm{GaN}$ power transistor which operates in the range of $650 \mathrm{~V} / 30 \mathrm{~A}$. Figure 1 provides a bottom and a top view of the tested $\mathrm{GaN}$ transistor package. The device package allows to study the temperature dependency of the GaN HEMT characteristics from low temperature $\left(5^{\circ} \mathrm{C}\right)$ to high temperature $\left(105^{\circ} \mathrm{C}\right)$. Figure 2 illustrates the p-AlGaN gate formed over the undoped $\mathrm{AlGaN} / \mathrm{GaN}$ heterostructure [11]. The p-AlGaN lifts up the potential at the channel, which enables normally-off operation.

The static characterization is performed using AMCAD pulsed I-V system. The pulses setting is fixed at a pulse frequency of $100 \mathrm{~Hz}$ with a gate pulse duty cycle of $0.04 \%$. The pulse width of $4 \mu$ s is short enough to ensure iso-thermal measurement of pulsed I-V GaN HEMT characteristics. The used I-V pulsed probes have a high measurement accuracy, which is equal to $\pm 100 \mathrm{~mA}$.

The tested GaN HEMT (DUT) is characterized at temperature ranging from $5{ }^{\circ} \mathrm{C}$ to $105^{\circ} \mathrm{C}$ in order to study the effect of temperature on $\mathrm{GaN}$ power transistors. The temperature is fixed by a Peltier heater plate. The I-V pulsed bench with associated instruments are shown in Figure 3.

The measured output characteristic curves for a gate-to-source voltage $\left(\mathrm{V}_{\mathrm{GS}}\right)$ equals to $6 \mathrm{~V}$ under operating temperatures equal to $5^{\circ} \mathrm{C}, 25^{\circ} \mathrm{C}, 75^{\circ} \mathrm{C}$ and $105^{\circ} \mathrm{C}$ are shown in Figure 4 (a). As observed, the drain current $\mathrm{I}_{\mathrm{D}}$ is modulated by the voltage $\mathrm{V}_{\mathrm{GS}}$. The transfer characteristic is obtained for a drain-source voltage $\left(\mathrm{V}_{\mathrm{DS}}\right)$ equals to $2 \mathrm{~V}$ and for various temperatures equal to $5^{\circ} \mathrm{C}, 25^{\circ} \mathrm{C}, 75^{\circ} \mathrm{C}$ and $105^{\circ} \mathrm{C}$ see Figure $4(\mathbf{b})$. The tested device has the advantage of safe normally-off operation for temperature up to $105^{\circ} \mathrm{C}$.

According to the output characteristic in Figure 4 (a), the evolution of the following electrical parameters are extracted: the on-state resistance, the threshold voltage. From the transfer characteristic in Figure 4 (b), the evolution of the transconductance $\mathrm{g}_{\mathrm{m}}$ versus temperature is determined. 


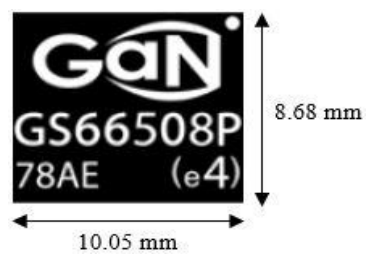

(a)

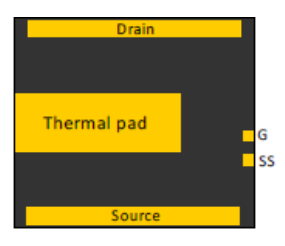

(b)

Fig. 1. GS66508P package [10]: (a) Top view; (b) bottom view

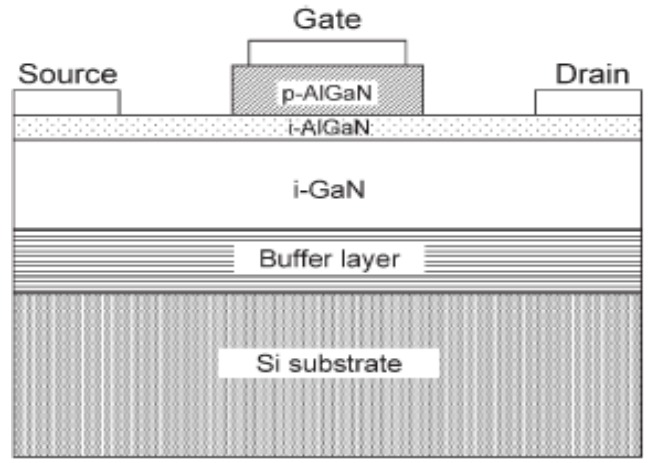

Fig. 2. Schematic illustration of the tested GaN HEMT power transistor structure [11]

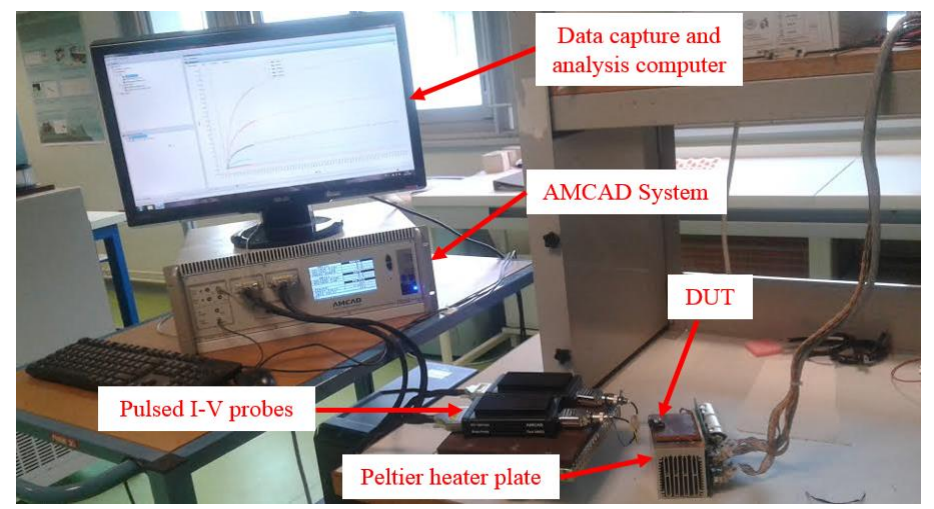

Fig. 3. I-V pulsed bench with associated instruments

\subsection{On-state resistance $\left(\mathbf{R}_{\mathrm{DS}(\mathrm{ON})}\right)$}

The $\mathrm{R}_{\mathrm{DSON}}$ is defined as the inverse of the slope of output characteristics in the linear region and it calculated by the following equation:

$$
\left.R_{D S(O N)}=\frac{\Delta I_{D}}{\Delta V_{D S}}\right)_{V_{G S}=6 V, V_{D S} \rightarrow 0 V}^{-1} .
$$




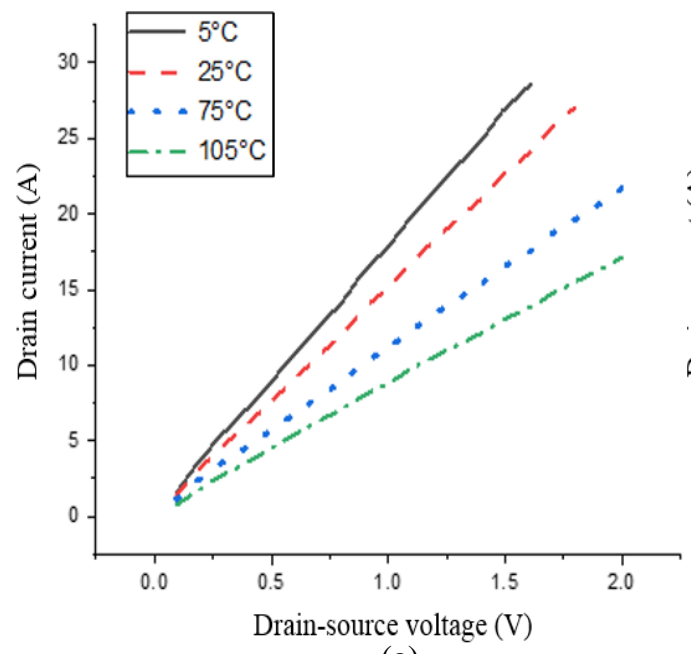

(a)

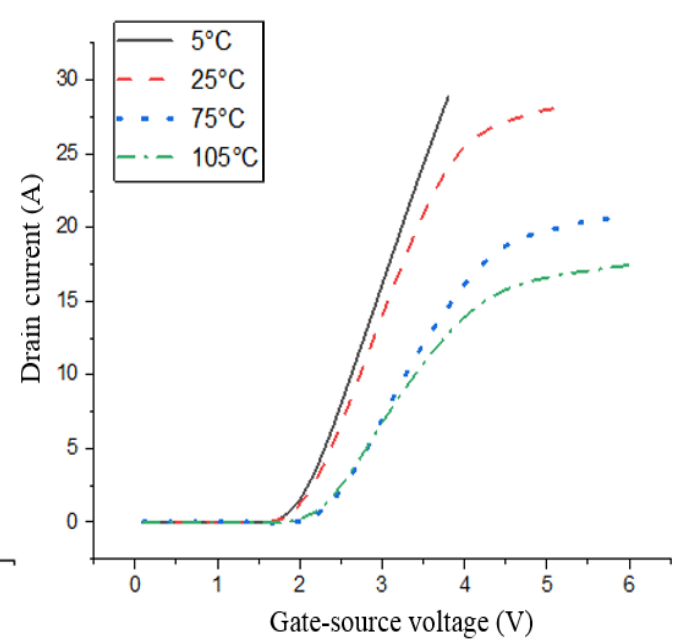

(b)

Fig. 4. (a) Output characteristic of GaN HEMT at $\mathrm{V}_{\mathrm{GS}}=6 \mathrm{~V}$; (b) Transfer characteristic of GaN HEMT at $V_{D S}=2 \mathrm{~V}$ for various temperatures: $5^{\circ} \mathrm{C}, 25^{\circ} \mathrm{C}, 75^{\circ} \mathrm{C}$ and $105^{\circ} \mathrm{C}$.

The measurement conditions of normalized $\mathrm{R}_{\mathrm{DS}(\mathrm{ON})}$ are: $\mathrm{V}_{\mathrm{GS}}=6 \mathrm{~V}$ and varying temperature from $5^{\circ} \mathrm{C}$ to $105^{\circ} \mathrm{C}$. Figure 5 shows the variation of the normalized $\mathrm{R}_{\mathrm{DS}(\mathrm{ON})}$ versus temperature. An increasing of $180 \%$ in on-state resistance at $105^{\circ} \mathrm{C}$ can be observed compared to its value at $5^{\circ} \mathrm{C}$.

The temperature dependency of $\mathrm{R}_{\mathrm{DS}(\mathrm{ON})}$ is due to the impact of temperature on the channel between the source and gate contacts [12]. In fact, if the device temperature is raised, the lowfield electron mobility in the channel is decreased [13], and a proportional increase of the channel resistance related to the drain-source resistance $\left(\mathrm{R}_{\mathrm{DS}}\right)$ can be expected. This result is also confirmed in [14] which is suggested to use GaN HEMT transistors with higher 2-D electron gas (2DEG) channel density for enhanced performances.

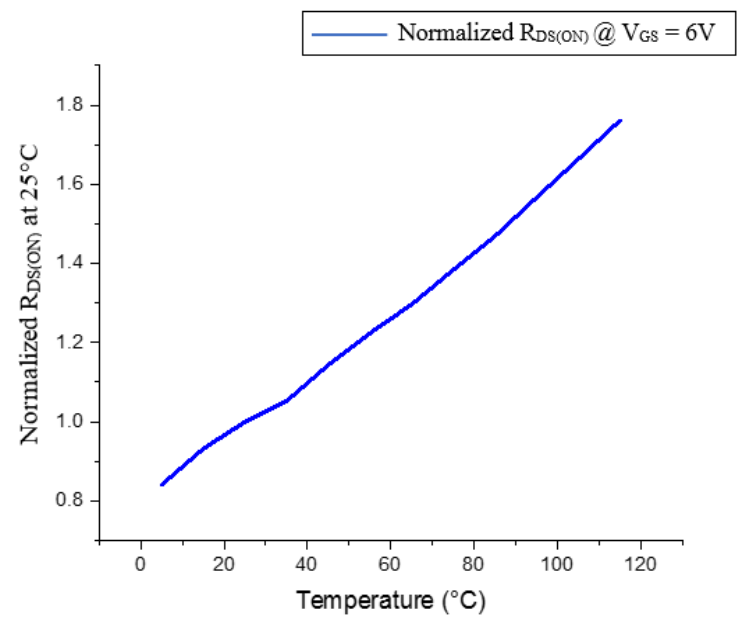

Fig. 5. Normalized $\mathrm{R}_{\mathrm{DS}(\mathrm{ON})}$ as a function of temperature at $\mathrm{V}_{\mathrm{GS}}=6 \mathrm{~V}$ 


\subsection{Threshold voltage $\left(\mathrm{V}_{\mathrm{TH}}\right)$}

The $\mathrm{V}_{\mathrm{TH}}$ is extracted using Extrapolation in the Linear Region (ELR) method [15]. The temperature dependency of the extracted threshold voltage is given in Figure 6 (a). As shown in this figure, the threshold voltage of GaN HEMT at $105^{\circ} \mathrm{C}$ decreases about $12 \%$ compared to their values at $5^{\circ} \mathrm{C}$.

The dependency of $\mathrm{V}_{\mathrm{TH}}$ on temperature is due to holes injected from the metal to the $\mathrm{p}-\mathrm{GaN}$ layer. The injected holes are accumulated at the $\mathrm{p}-\mathrm{GaN} / \mathrm{AlGaN}$ interface. This lead to a negative shift in threshold voltage, which can also be observed in [16]. Recent studies [17] shows that using hydrogen plasma treatment instead of etching technology may compensate holes in the pGaN layer above the two dimensional electron gas (2DEG) channel to release electrons in the 2DEG channel and form high resistivity area to reduce leakage current and increase threshold voltage stability.

\subsection{Transconductance $\left(\mathrm{g}_{\mathrm{m}}\right)$}

The $g_{m}$ quantifies the drain current variation with a gate-source voltage variation while keeping the drain-source voltage constant (bias voltage). It is defined by the following equation, while $\mathrm{V}_{\mathrm{DS}}$ is the bias voltage.

$$
\left.g_{m}=\frac{\partial I_{D}}{\partial V_{G S}}\right)_{V_{D S}=2 V} .
$$

Figure 6 (b) shows the variations of the transconductance $\mathrm{g}_{\mathrm{m}}$ as a function of temperature. As shown in this figure, the transconductance $\mathrm{g}_{\mathrm{m}}$ at $105^{\circ} \mathrm{C}$ decreases about $58.38 \%$ compared to their values at $5^{\circ} \mathrm{C}$. The decreasing of $\mathrm{g}_{\mathrm{m}}$ with the increase of temperature is due to the decrease of both the electron mobility in the channel and the electron velocity [18]. The decrease of the transconductance when increasing temperature is observed in [19] which is confirmed that the channel mobility decreases with the increase of temperature [20].

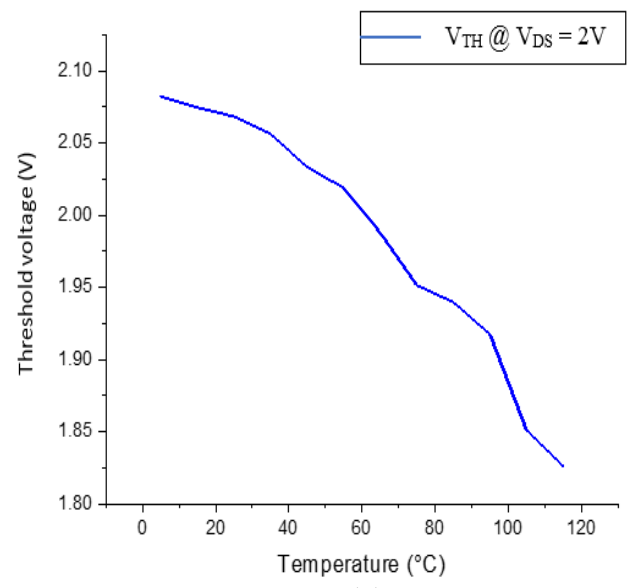

(a)

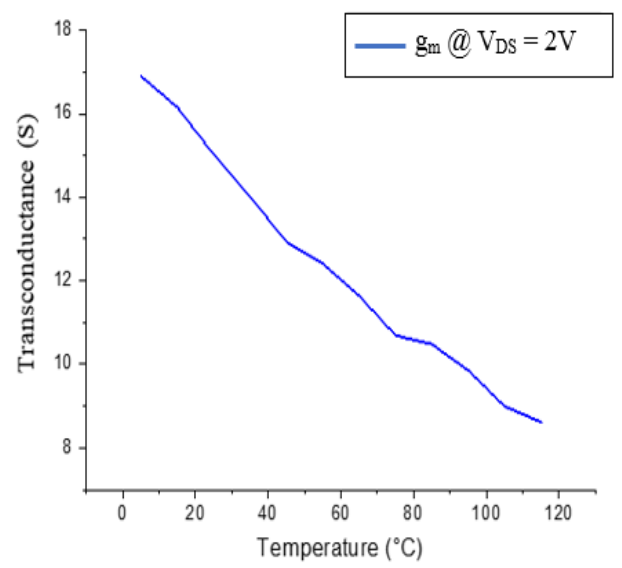

(b)

Fig. 6. (a) Threshold voltage; (b) Transconductance as a function of temperature at $\mathrm{V}_{D S}=2 \mathrm{~V}$ 


\subsection{Gate leakage current}

The gate leakage current is defined as the leakage that occurs when the specified voltage is applied across the gate and source with drain and source short-circuited. The leakage current measurements were performed by using Keithly 2636B SourceMeter.

Figure 7 shows the evolution of the gate leakage current as a function of temperature. As observed, the current $\mathrm{I}_{\mathrm{GSS}}$ is increased by $77.77 \%$ when varying temperature from $5^{\circ} \mathrm{C}$ to $105^{\circ} \mathrm{C}$. It was demonstrated in reference [21] that increasing temperature may reduce the schottky barrier height at the metal/p-GaN contact and, consequently, increase the gate leakage current. Moreover, in $\mathrm{p}-\mathrm{GaN} / \mathrm{AlGaN} / \mathrm{GaN}$ heterostructure, the reduction of the Schottky barrier height at the metal/p-GaN gate enhances the tunneling of holes through the barrier [22]. Then, as highlighted by Hwang et al. [23], the enhancement of holes injection leads not only to a negative shift of the $\mathrm{V}_{\mathrm{TH}}$ but also to an increase in the leakage current in $\mathrm{p}-\mathrm{GaN}$ HEMT. The increase in the leakage gate current when increasing temperature is also observed in [24], which is attributed to the lowering of the Schottky barrier height of the metal/p-GaN gate.

\section{Modeling temperature dependency}

The purpose of this part is to model the temperature dependency of the GaN HEMT in order to evaluate the effects of GaN HEMT on the power efficiency of the DC-DC converters by a SPICE simulation approach. Figure 8 shows the studied DC-DC boost converter, which is a $12 / 24 \mathrm{~V}$ boost converter with an output power equals to $180 \mathrm{~W}$. The tested device (DUT) is the SPICE Electro-thermal model of the GaN HEMT.

The proposed drain current model of the DUT is a non-segmented, smooth and continuous equation inspired from the Motorola Electro-thermal Model (MET) developed by Curtice et al. [25] and described in [26].

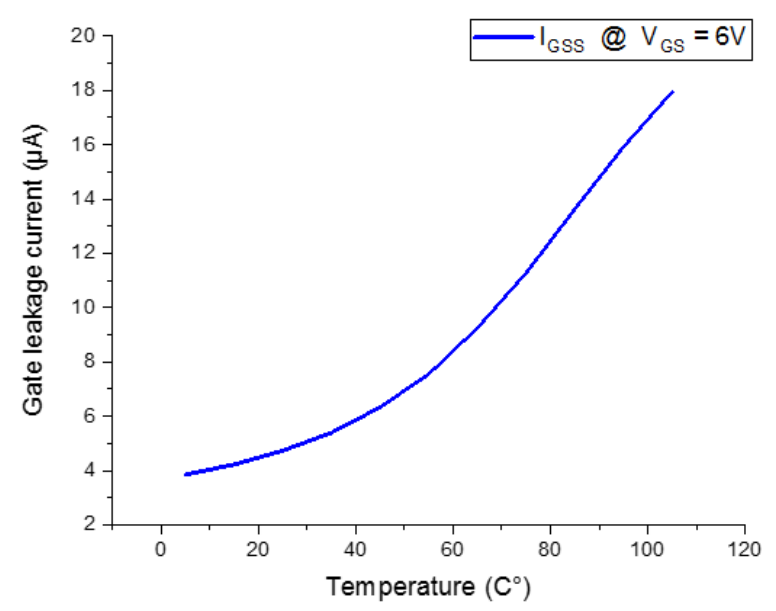

Fig. 7. Gate leakage current as a function of temperature at $V_{G S}=6 \mathrm{~V}$ 


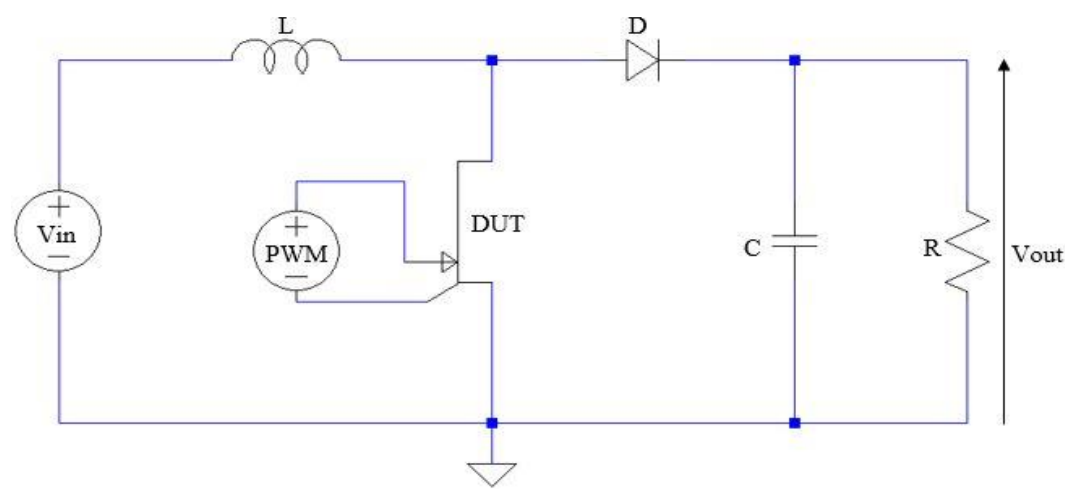

Fig. 8. $\mathrm{DC}-\mathrm{DC}$ boost converter with $\mathrm{L}=21.41 \mu \mathrm{H}$, Vin $=12 \mathrm{~V}$, Vout $=24 \mathrm{~V}, \mathrm{C}=90.9 \mu \mathrm{F}$ and $\mathrm{R}=1.71$ $\Omega$. The switching conditions of the DUT transistor are: $\mathrm{f}=50 \mathrm{kHz}$ and duty-cycle $=50 \%$.

The proposed drain current equation is shown as follows:

$$
\left\{\begin{array}{l}
I_{D S}=K(T) \cdot \log \left[1+\exp \left(\frac{V_{G S}-b}{c}\right)\right] \cdot \frac{\left(m+n \cdot V_{G S}\right) V_{D S}}{1+P(T) \cdot\left(d+e \cdot V_{G S}\right) V_{D S}}, \mathrm{~V}_{D S} \geq 0 \\
K(T)=K \cdot\left[1+T_{C 1} \cdot(T-25)+T_{C 2} \cdot(T-25)^{2}\right] \\
P(T)=P \cdot\left[1+T_{C 3} \cdot(T-25)+T_{C 4} \cdot(T-25)^{2}\right]
\end{array} .\right.
$$

Where $\mathrm{K}$ is the device forward transconductance $\left(\mathrm{A} . \mathrm{V}^{-1}\right)$ parameter at $25^{\circ} \mathrm{C}, \mathrm{P}$ is the output conductance $\left(\mathrm{V}^{-1}\right)$ at $25^{\circ} \mathrm{C}, \mathrm{b}$ and $\mathrm{c}$ are related parameters of the transfer characteristic, while $\mathrm{m}$, $\mathrm{n}, \mathrm{d}$ and $\mathrm{e}$ are related parameters of the output characteristic. Tc1, $\mathrm{T}_{\mathrm{C} 2}, \mathrm{~T}_{\mathrm{C} 3}$ and $\mathrm{Tc} 4$ are temperature coefficients. These parameters are extracted by using the Levenberg-Marquardt algorithm [27] as shown in Table 1.

The conduction power loss $\left(\mathrm{P}_{\mathrm{C}}\right)$ is defined by:

$$
P_{c}=\frac{1}{T_{\text {on }}} \int_{0}^{T_{\text {oN }}} i_{d s} \cdot v_{d s} \cdot d t
$$

Where, $\mathrm{i}_{\mathrm{ds}}$ is instantaneous drain current, $\mathrm{v}_{\mathrm{ds}}$ is the instantaneous drain voltage and $\mathrm{T}_{\mathrm{on}}$ is the conduction time which is given by:

$$
T_{\text {on }}=\frac{d_{c}}{f} \text {. }
$$

Where, $d_{c}$ is the duty cycle and $f$ is the frequency.

Figure 9 shows the conduction power losses of the DUT used in the DC-DC converter of Figure 8 at various junction temperatures: $25^{\circ} \mathrm{C}, 70^{\circ} \mathrm{C}$ and $105^{\circ} \mathrm{C}$. From Figure 9 , an increase in conduction power losses is observed, which is mainly due to the increase of the dynamic onstate resistance of the DUT when increasing temperature. 
Table 1. Extracted Electrothermal SPICE model parameters

\begin{tabular}{lllllll}
\hline Parameter & $\mathrm{K}$ & $\mathrm{b}$ & $\mathrm{c}$ & $\mathrm{m}$ & $\mathrm{n}$ & $\mathrm{P}$ \\
\hline Value & 1.42 & 1.65 & 0.14 & 8.12 & -1.15 & 0.75 \\
\hline Parameter & $\mathrm{d}$ & $\mathrm{e}$ & $\mathrm{T}_{\mathrm{C} 1}$ & $\mathrm{~T}_{\mathrm{C} 2}$ & $\mathrm{~T}_{\mathrm{C} 3}$ & $\mathrm{~T}_{\mathrm{C} 4}$ \\
\hline Value & 1.94 & -0.35 & $-8.02 \mathrm{E}-3$ & $3.22 \mathrm{E}-5$ & $-3.75 \mathrm{E}-3$ & $4.01 \mathrm{E}-6$ \\
\hline
\end{tabular}

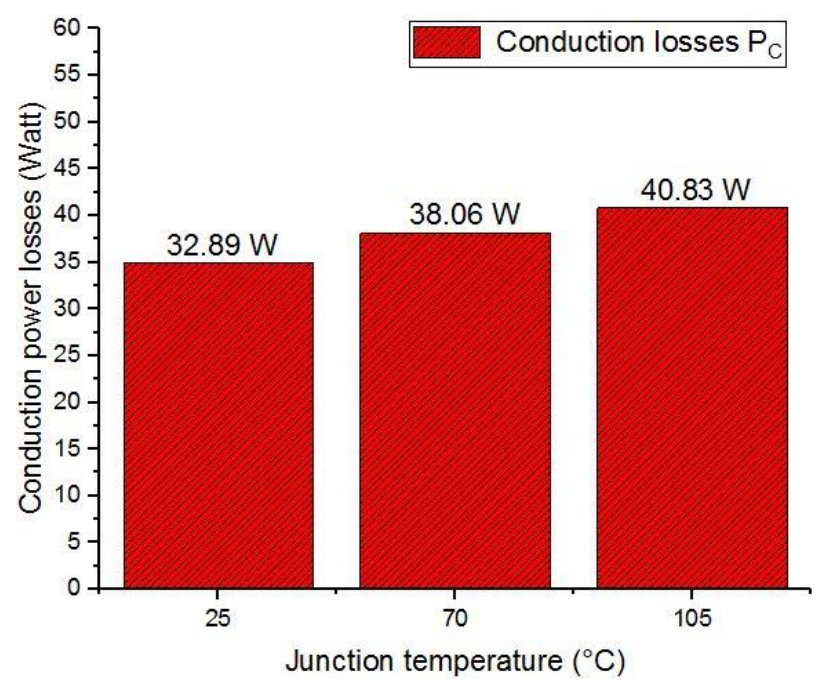

Fig. 9. Conduction power losses of $\mathrm{GaN}$ HEMT at $\mathrm{T}_{\mathrm{J}}=25^{\circ} \mathrm{C}, 70^{\circ} \mathrm{C}$ and $105^{\circ} \mathrm{C}$

\section{Conclusion}

In conclusion, the temperature dependency of GaN HEMT static characteristics has been studied based on experimental measurements. The decreases in $\mathrm{R}_{\mathrm{DS}(\mathrm{ON})}$, $\mathrm{I}_{\mathrm{DS}}$ and $\mathrm{g}_{\mathrm{m}}$ with the increase of temperature are due to the decrease in electron mobility. The increase in $\mathrm{I}_{\mathrm{GSS}}$ and the negative shift of $\mathrm{V}_{\mathrm{TH}}$ when increasing temperature is attributed to the lowering of the Schottky barrier height of the metal/p-GaN gate and to hole injection at the metal/p-GaN. It is suggested to use GaN HEMT transistors with hydrogen plasma treatment instead of etching technology to reduce leakage current and increase threshold voltage stability. Upon cooling after high temperature characterization at $105{ }^{\circ} \mathrm{C}$, GaN HEMT transistors showed recovered output and transfer characteristics. The effect of increasing the operational temperature of the GaN HEMT transistors on a DC power converter is verified by modeling the thermal characteristics of the GaN HEMT. Such an investigation is important particularly to understand the cause of deterioration of GaN HEMT electrical performances at high temperatures. The temperature dependency of GaN HEMT dynamic characteristics will be studied in the next work in order to take into account the switching losses. This enable an accurate design of power converters with GaN HEMTs for renewable energy applications by a simulation approach. 


\section{Acknowledgments}

This work is financially supported by the PHC Toubkal project (code TBK/17/41).

\section{References}

[1] Global EV Outlook 2017, International Energy Agency, 2017.

[2] Renewable Energy Market Insight, GaN Systems Inc, 2018.

[3] Chen, Feida, Xiaofeng Ding, and Ehtisham Lodhi. "Efficiency and Current Harmonics Comparison Between SiC and Si Based Inverters for Microgrids." Energy Procedia 103 (2016): 298-303.

[4] Bhat, Ishwara. "Physical properties of gallium nitride and related III-V nitrides." Wide Bandgap Semiconductor Power Devices. Woodhead Publishing, 2019. 43-77.

[5] Perkins, S., et al. "A comprehensive comparison of the static performance of commercial GaN-onSi devices." Wide Bandgap Power Devices and Applications (WiPDA), 2017 IEEE 5th Workshop on. IEEE, 2017.

[6] Kaplar, R. J., et al. "Characterization and reliability of SiC-and GaN-based power transistors for renewable energy applications." Energytech, 2012 IEEE. IEEE, 2012.

[7] Ioinovici, Adrian. Power Electronics and Energy Conversion Systems: Fundamentals and Hardswitching Converters. Volume 1. Wiley, 2013.

[8] Chihani, Omar, et al. "Temperature and voltage effects on HTRB and HTGB stresses for AlGaN/GaN HEMTs." 2018 IEEE International Reliability Physics Symposium (IRPS). IEEE, 2018.

[9] Chihani, Omar, et al. "Effect of HTRB lifetest on AlGaN/GaN HEMTs under different voltages and temperatures stresses." Microelectronics Reliability 88 (2018): 402-405.

[10] GS66508P Preliminary Datasheet, GaN_Systems_Inc. 2018.

[11] Uemoto, Yasuhiro, et al. "Gate injection transistor (GIT) - A normally-off AlGaN/GaN power transistor using conductivity modulation." IEEE Transactions on Electron Devices 54.12 (2007): 33933399.

[12] Kuzmik, J., et al. "Determination of channel temperature in AlGaN/GaN HEMTs grown on sapphire and silicon substrates using DC characterization method." IEEE transactions on electron devices 49.8 (2002): 1496-1498.

[13] J. D. Albrecht, R. P. Wang, R. P. Ruden, M. Farahmand, and K. F. Brennan, "Electron transport characteristics of GaN for high temperature device modeling," J. Appl. Phys., vol. 83, pp. 4777-4781, 1998.

[14] Wong, King-Yuen, Wanjun Chen, and Kevin J. Chen. "Characterization and analysis of the temperature-dependent on-resistance in $\mathrm{AlGaN} / \mathrm{GaN}$ lateral field-effect rectifiers." IEEE Transactions on Electron Devices 57.8 (2010): 1924-1929.

[15] Ortiz-Conde, Adelmo, et al. "A review of recent MOSFET threshold voltage extraction methods." Microelectronics Reliability", 42.4-5 (2002): 583-596.

[16] Matteo Meneghini, Oliver Hilt, Joachim Wuerfl and Gaudenzio Meneghesso, "Technology and Reliability of Normally-Off GaN HEMTs with p-Type Gate “, mdpi,energie 2017, pp. 15-17, 2017

[17] Hao, Ronghui, et al. "Normally-off p-GaN/AlGaN/GaN high electron mobility transistors using hydrogen plasma treatment." Applied Physics Letters 109.15 (2016): 152106.

[18] Arulkumaran, S., et al. "High-temperature effects of AlGaN/GaN high-electron-mobility transistors on sapphire and semi-insulating SiC substrates." Applied physics letters 80.12 (2002): 2186218

[19] Kühn, Jutta. AlGaN-GaN-HEMT Power Amplifiers With Optimized Power-Added Efficiency for X-Band Applications. Vol. 62. KIT Scientific Publishing, 2011.

[20] Maeda, Narihiko, et al. "High-temperature electron transport properties in $\mathrm{AlGaN} / \mathrm{GaN}$ heterostructures." Applied Physics Letters 79.11 (2001): 1634-1636.

[21] Aktas, Ozgur, et al. "High temperature characteristics of AlGaN/GaN modulation doped fieldeffect transistors." Applied Physics Letters 69.25 (1996): 3872-3874.

[22] Greco, Giuseppe, et al. "Effects of annealing treatments on the properties of Al/Ti/p-GaN interfaces for normally off p-GaN HEMTs." IEEE Transactions on Electron Devices 63.7 (2016): 2735-2741. 
[23] Giuseppe Greco, Ferdinando Iucolano, Fabrizio Roccaforte, "Review of technology for normallyoff HEMTs with p-GaN gate", Materials Science in Semiconductor Processing, pp. , 2017, ISSN 13698001.

[24] I. Hwang et al., "p-GaN gate HEMTs with tungsten gate metal for high threshold voltage and low gate current,” IEEE Electron Device Lett., vol. 34, no. 2, pp. 202-204, Feb. 2013

[25] W. Curtice et al., "A New Dynamic Electro-Thermal Nonlinear Model for Silicon RF LDMOS FETs,” IEEE MTT-S International Microwave Symposium Digest, 1999, p. 419.

[26] Bouchour, Al Mehdi, et al. "Modeling of power GaN HEMT for switching circuits applications using Levenberg-Marquardt Algorithm," In : International Symposium on Advanced Electrical and Communication Technologies (ISAECT), 2018 International Conference on. IEEE, 2018.

[27] Jouha, Wadia, et al. "Silicon Carbide Power MOSFET Model: An Accurate Parameter Extraction Method Based on Levenberg- Marquardt Algorithm." IEEE Transactions on Power Electronics (2018). 